Article

\title{
Investigation of the Carbon Monoxide Gas Sensing Characteristics of Tin Oxide Mixed Cerium Oxide Thin Films
}

\author{
Sardar M. A. Durrani *, Mohammad F. Al-Kuhaili, Imran A. Bakhtiari and \\ Muhammad B. Haider
}

Physics Department, King Fahd University of Petroleum and Minerals, Dhahran 31261, Saudi Arabia; E-Mails: kuhaili@kfupm.edu.sa (M.F.A.-K.); iab@kfupm.edu.sa (I.A.B.); mhaider@kfupm.edu.sa (M.B.H.)

* Author to whom correspondence should be addressed; E-Mail: smayub@kfupm.edu.sa; Tel.: +966-3-860-3555; Fax: +966-3-860-4281.

Received: 6 January 2012; in revised form: 11 February 2012 / Accepted: 16 February 2012 / Published: 27 February 2012

\begin{abstract}
Thin films of tin oxide mixed cerium oxide were grown on unheated substrates by physical vapor deposition. The films were annealed in air at $500{ }^{\circ} \mathrm{C}$ for two hours, and were characterized using X-ray photoelectron spectroscopy, atomic force microscopy and optical spectrophotometry. X-ray photoelectron spectroscopy and atomic force microscopy results reveal that the films were highly porous and porosity of our films was found to be in the range of $11.6-21.7 \%$. The films were investigated for the detection of carbon monoxide, and were found to be highly sensitive. We found that $430{ }^{\circ} \mathrm{C}$ was the optimum operating temperature for sensing $\mathrm{CO}$ gas at concentrations as low as $5 \mathrm{ppm}$. Our sensors exhibited fast response and recovery times of $26 \mathrm{~s}$ and $30 \mathrm{~s}$, respectively.
\end{abstract}

Keywords: thin film; AFM; XPS; $\mathrm{CeO}_{2} ; \mathrm{SnO}_{2}$; $\mathrm{CO}$ sensor; semiconductor gas sensor

\section{Introduction}

There is an ever-increasing demand for gas sensors in various fields. Particular attention has been devoted to the monitoring of carbon monoxide (CO). More precise control of the air/fuel ratio in a combustion processes can yield significant gains in efficiency and result in substantial savings in fuel consumption. The flue gas concentration of $\mathrm{CO}$ is a reliable and accurate indication of the completeness of combustion, as it is the most sensitive indicator of unburned combustible losses. Metal oxide semiconductors have been employed in the detection of CO. One of the advantages of 
these materials is that they enable high temperature operation, making them unique for hostile industrial applications. Moreover, many gas reactions are plausible only at such elevated temperatures. The basic property of metal oxides that is of interest in gas-sensing applications is the dependence of their electrical conductivity on the ambient gas. Most metal oxide semiconductors are naturally of n-type conductivity due to the presence of a large number of oxygen vacancies. When such a material is exposed to the atmosphere, oxygen molecules are chemisorbed to the grain boundaries and pick up electrons from the conduction band and create a space charge layer between the grains [1]. This leads to the formation of Schottky barriers at the surfaces of the grains, and increases the resistivity of the material [2]. Exposure of the material to reducing gases (such as carbon monoxide) causes a reaction of these gases with the chemisorbed oxygen, increasing the electronic conduction and reducing the resistance [1,2]. The sensing properties are based on surface reactions and are greatly affected by the microstructure of the material [3].Thin films offer the added advantage of higher surface-to-volume ratio. In addition to the choice of the semiconducting oxide, other film parameters that are widely known to affect the sensing properties of a thin film are surface roughness, stoichiometry, and porosity, basicity. Most of the commercially available gas sensors are based on thick-film metal oxide materials deposited on ceramic heater substrates [4]. A common shortcoming of such thick-film devices is their high level of heating power consumption. This level can be reduced by about one-order of magnitude using micro-machined heater substrates [4]; in addition their response and recovery times are much longer compared to the thin film sensors. The established state-of-the-art in silicon micromachining is still the use of evaporated or sputtered thin-film metal oxide materials [4].

Several metal oxides have been tested as CO gas sensors. Tin oxide based gas sensors are among the most widely used semiconductors for detecting $\mathrm{CO}$ [5-9]. More recently pure $\mathrm{CeO}_{2}$ thin films have also been investigated for their application as $\mathrm{CO}$ gas sensors [10], and were found to be highly sensitive to $\mathrm{CO}$. These high sensitivities were attributed mainly to the film porosity. $\mathrm{CeO}_{2}$ films are known to be highly porous [3,11]. It is known that additions of various second-phase oxides and/or catalysts (such as $\mathrm{Pd}, \mathrm{Pt}$, and $\mathrm{CuO}$ etc.) improve sensing characteristics for $\mathrm{CO}$ detections [5-7]. Motivated by the high sensitivity of $\mathrm{SnO}_{2}$ thin films and the high porosity of $\mathrm{CeO}_{2}$ thin films, we prepared $\mathrm{SnO}_{2}$ mixed $\mathrm{CeO}_{2}$ thin films. Here we report the significant improvement in term of response time and detection limit observed for these mixed films.

\section{Experimental Section}

Thin films of $\mathrm{SnO}_{2}$ mixed $\mathrm{CeO}_{2}$ were prepared by co-evaporation using physical vapor deposition. For this purpose $\mathrm{CeO}_{2}$ was evaporated by e-beam while $\mathrm{SnO}_{2}$ was evaporated by thermal evaporation simultaneously. Ratios of the two materials were controlled by quartz crystal monitor. The evaporation

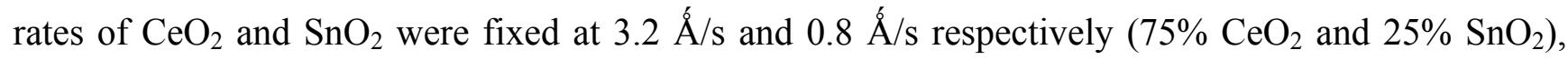
with the total rate of $4 \AA / \mathrm{s}$. The films were prepared in a Leybold L560 box coater pumped by a turbomolecular pump. The system was initially pumped to a base pressure of $1 \times 10^{-4} \mathrm{~Pa}$. Before deposition, the materials were slowly outgassed, with a shutter blocking the vapors from reaching the substrate. The films were deposited on unheated substrates. The substrates were rotating during the deposition, and the source-to-substrate distance was $40 \mathrm{~cm}$. The evaporation rates and thickness of the films were controlled by a quartz crystal thickness monitor. For different purposes of film 
characterization, the films were simultaneously deposited on tantalum substrates (for X-ray photoelectron spectroscopy, XPS), fused silica substrates (for optical measurements), and alumina substrates (for gas sensing measurements). After the films were deposited, they were removed from the coating chamber and exposed to the ambient atmosphere. Subsequently, all samples were annealed in air at $500{ }^{\circ} \mathrm{C}$ for two hours in order to thermally stabilize the films prior to sensing measurements. XPS was performed using a VG Scientific MKII spectrometer with an Al Ka (1,486.6 eV) X-ray source. The instrumental resolution was $1.2 \mathrm{eV}$, with a slit width of $0.6 \mathrm{~cm}$. Prior to the XPS analysis; the samples were transferred in air to the XPS analysis chamber. The $\mathrm{C} 1 \mathrm{~s}$ peak of hydrocarbon contamination, at a binding energy of $284.5 \mathrm{eV}$, was used as an energy reference. During the XPS analysis, the samples were maintained at ambient temperature at a pressure of $5 \times 10^{-7} \mathrm{~Pa}$. Normalincidence transmittance and reflectance, over the wavelength range 300-1,200 $\mathrm{nm}$, were measured using a Jasco V-570 double beam spectrophotometer. The thicknesses of the annealed films were measured using a surface profilometer (AMBIOS XP-2), and was found to be $220 \mathrm{~nm}$. The AFM images of the sample were acquired using tapping mode of Digital Instrument's (VEECO) Innova SPM and Nano-Drive Controller system. For these images the Phosphorus (n) doped Silicon probes were used. These probes have the nominal tip radius of less than $10 \mathrm{~nm}$, tip height of 15 to $20 \mu \mathrm{m}$ and the resonant frequency of about $300 \mathrm{kHz}$. The AFM images were processed using Digital Instruments SPMLab Version 7.0 software for leveling and noise removal. The gas-sensing measurements were made on the films deposited on top of alumina substrates with platinum interdigitated electrodes (for electrical measurements). A platinum heater was printed on the backside of the substrate. The gas-sensing measurements were carried out in the environmental test chamber shown in Figure 1.

Figure 1. Experimental setup for sensitivity measurements.

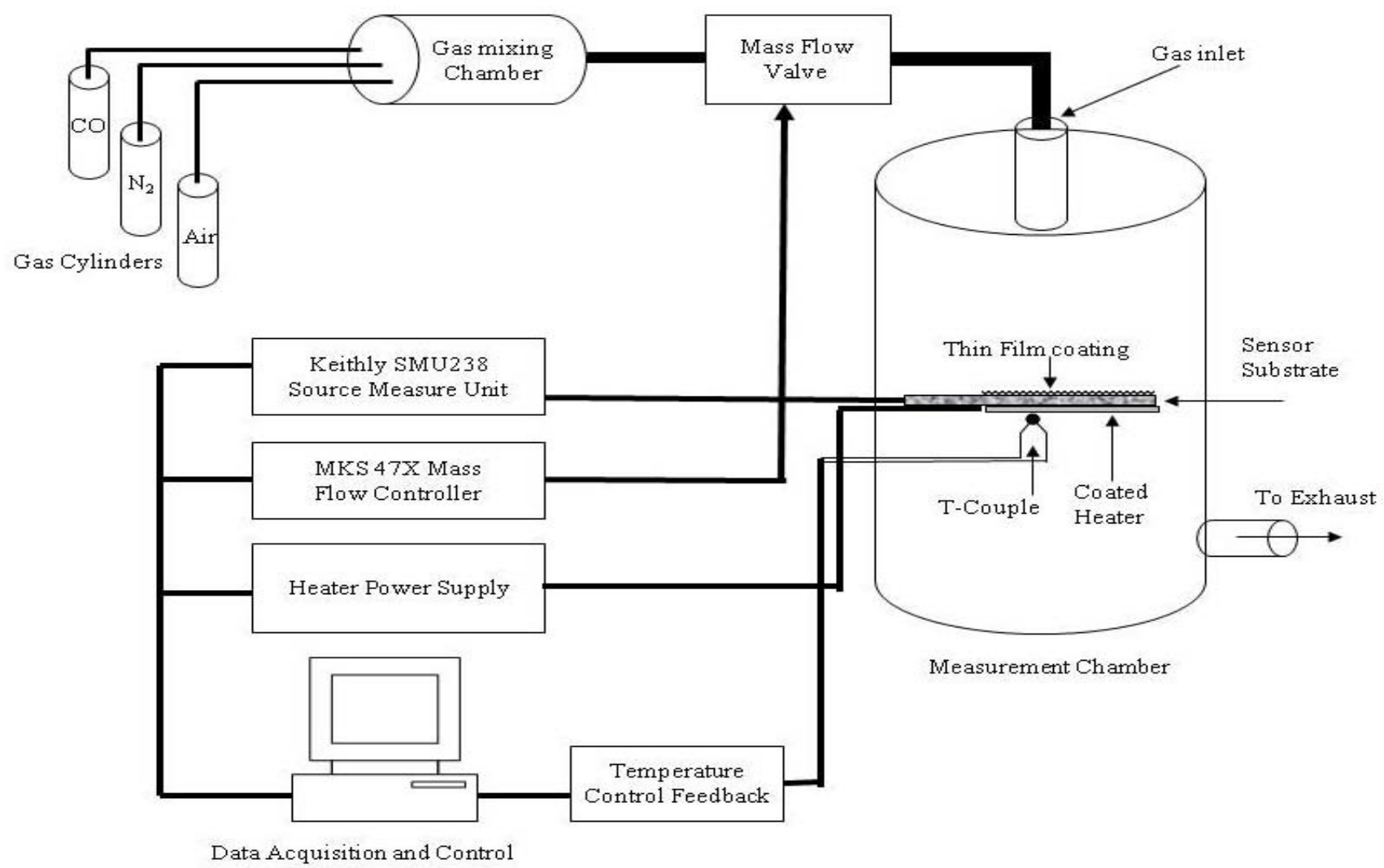


The desired $\mathrm{CO}$ concentration in ppm was achieved using a stainless steel gas mixing chamber in combination with MKS 647 controller and the 100SCCM mass flow controller. A Leybold model combiVAC 2T digital pressure measurement unit for low pressure and a 200-PSI high pressure gauge from USG was used to measure the chamber pressures. The chamber was first vacuumed to the pressure level of $\sim 1 \times 10^{-7}$ mbar using Leybold Model PT 50 pumping system which is composed of a roughing and turbo molecular pumps. Initially a known volume of High Purity $\mathrm{CO}$ gas was added to the mixing chamber using the 100 SCCM Mass flow controller and then it was mixed with the required volume of air as buffer gas to achieve the desired $\mathrm{CO}$ concentration. The concentration of $\mathrm{CO}$ was varied between 5-5,000 ppm. The volume of gas to be injected was controlled by the duration (dwell time) of valve opening and its flow rate. The temperature of the sensor was controlled with a programmable BK Precision power supply (BK1770), K-type thermocouple (feedback element) and a PC PID temperature controller. The sensor temperature was varied in the range $300-600{ }^{\circ} \mathrm{C}$. The sensor current (under a given bias voltage) was measured using a source measure unit (Keithly 238). The resistance of the films was calculated as the ratio between the applied bias voltage and the measured current. A personal computer was used to control all the operations (gas injection, temperature measurement and control, and current measurement) using LABVIEW via a GPIB interface.

\section{Results}

\subsection{Chemical Analysis (XPS)}

The chemical state of the films was investigated using XPS. Figure 2 shows an XPS survey scan of a typical film. The scan shows sharp XPS and Auger lines due to the main constituents (Ce, Sn, and O), whose identification was based on published values [12].

Figure 2. XPS survey spectrum of the deposited films.

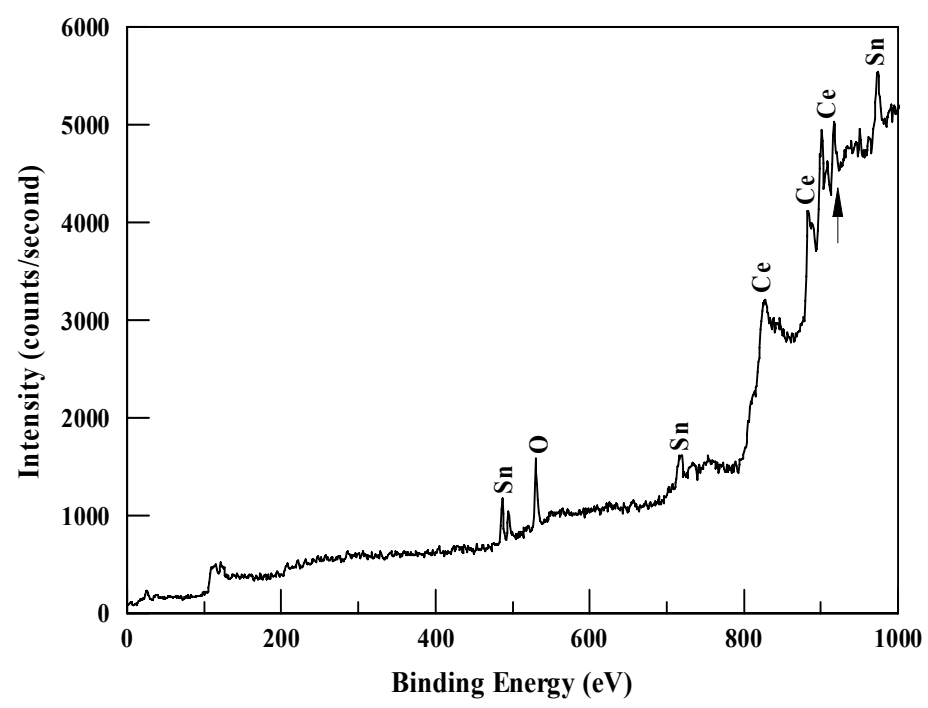

Detailed spectra in the $\mathrm{Ce} 3 \mathrm{~d}, \mathrm{Sn} 3 \mathrm{~d}$, and $\mathrm{O} 1$ s core level regions are shown in Figure $3 . \mathrm{CeO}_{2}$ has a relatively complex Ce $3 \mathrm{~d}$ XPS spectrum that consists of six peaks, which correspond to the three pairs of spin-orbit doublets of oxidized $\mathrm{CeO}_{2}$ [13]. The measured $\mathrm{Ce} 3 \mathrm{~d}$ spectrum (Figure 3(a)) clearly 
shows five peaks at binding energies of $882.4 \mathrm{eV}, 888.1 \mathrm{eV}, 897.8 \mathrm{eV}, 900.4 \mathrm{eV}$, and $906.7 \mathrm{eV}$. The first three peaks correspond to $\mathrm{Ce} 3 \mathrm{~d}_{5 / 2}$ and the last two peaks correspond to $\mathrm{Ce} 3 \mathrm{~d}_{3 / 2}$. An additional peak at a binding energy of $916.6 \mathrm{eV}$ was observed in the survey scan (shown by the arrow in Figure 2).

Figure 3. High resolution XPS spectra of the deposited films: (a) Ce 3d region: the assignment of the peaks to the two sublevels of Ce $3 \mathrm{~d}$ is shown, (b) Sn $3 \mathrm{~d}$ region, (c) $\mathrm{O} 1 \mathrm{~s}$ region: the spectrum is deconvoluted into three components and the experimental spectrum is represented by the circles.

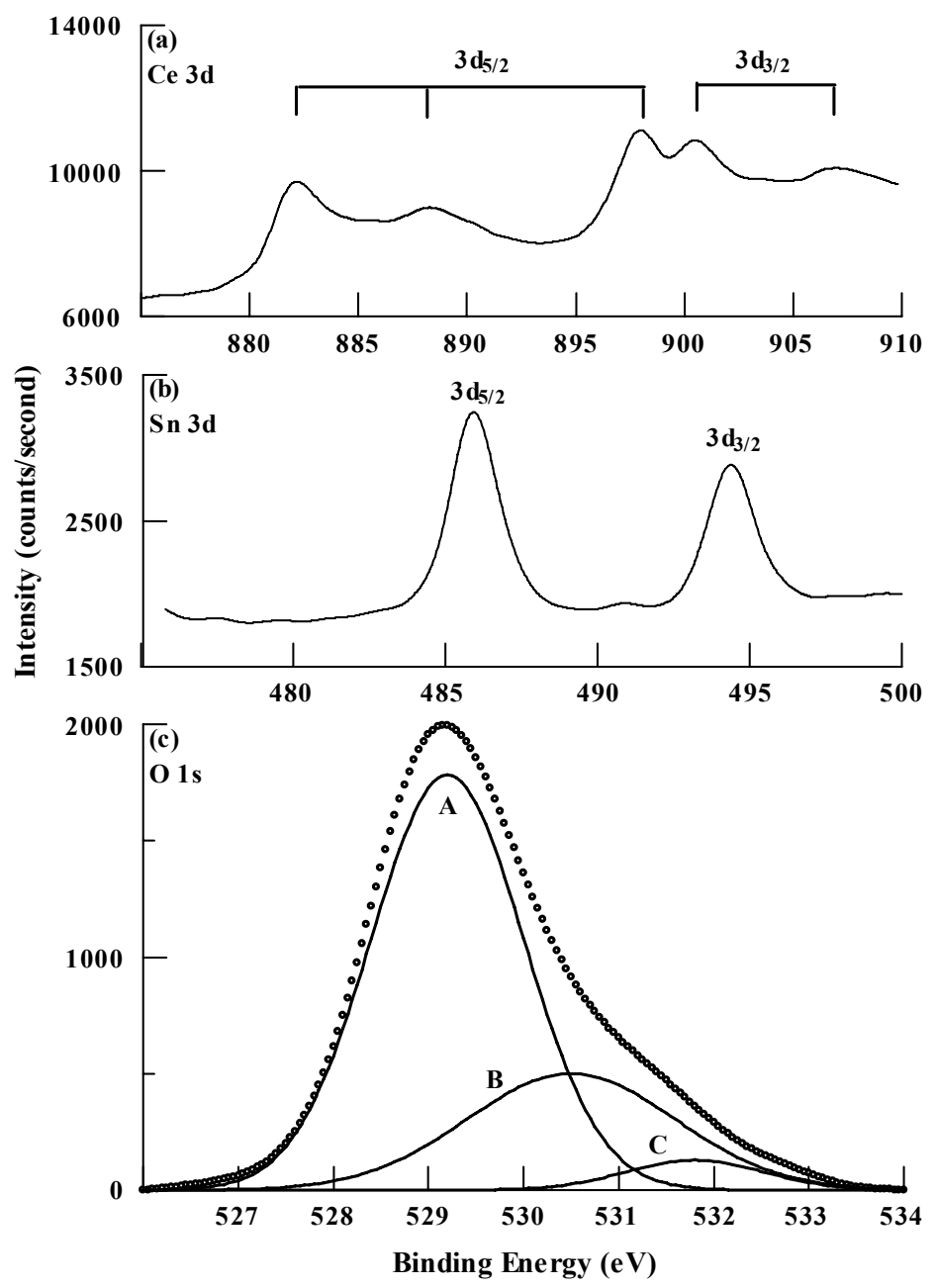

The binding energies of these peaks match very closely the reported values of the Ce $3 \mathrm{~d}$ six peaks of cerium in the $\mathrm{Ce}^{4+}$ oxidation state [14]. These results indicate that cerium was present in the films as $\mathrm{CeO}_{2}$. This is further supported by the presence of the peak at $916.6 \mathrm{eV}$, which is considered as a fingerprint of the $\mathrm{CeO}_{2}$ phase [15]. The $\mathrm{Sn} 3 \mathrm{~d}$ spectrum is shown in Figure 3(b). The spectrum shows the $\mathrm{Sn} 3 \mathrm{~d}_{5 / 2}$ and $\mathrm{Sn} 3 \mathrm{~d}_{3 / 2}$ peaks at binding energies of $485.9 \mathrm{eV}$ and $494.4 \mathrm{eV}$, respectively. The reported values for the binding energies of the $\mathrm{Sn} 3 \mathrm{~d}_{5 / 2}$ level in as-deposited tin oxide films were 486.6 in $\mathrm{Sn}^{4+}\left(\mathrm{SnO}_{2}\right)$ and $485.9 \mathrm{eV}$ in $\mathrm{Sn}^{2+}(\mathrm{SnO})$ [16,17]. However, upon annealing in an oxygen atmosphere at $527{ }^{\circ} \mathrm{C}$, tin oxide films became stoichiometric $\left(\mathrm{SnO}_{2}\right)$ with a binding energy of the $\mathrm{Sn}$ $3 \mathrm{~d}_{5 / 2}$ level at $486.1 \mathrm{eV}$ (i.e., a $0.5 \mathrm{eV}$ down shift) [16]. Based on these results, we can assume that the tin was mainly present in our films as substoichiometric $\mathrm{SnO}_{2}$. The atomic concentration of the 
elements was calculated from the normalized areas of the peaks, taking the atomic sensitivity factors into account. The accuracy of determining this ratio is $10 \%$. The atomic concentrations were 0.20 for cerium, 0.13 for tin, and 0.67 for oxygen. The O1s spectrum (Figure 3(c)) was deconvoluted into three components using a Gaussian/Lorenzian mixed function employing Shirley background correction. The lower-energy component (A) with a binding energy of $529.1 \mathrm{eV}$ corresponds to the Ce-O bond in $\mathrm{CeO}_{2}$ [16]. The medium-energy component (B) with a binding energy of $530.5 \mathrm{eV}$ corresponds to the $\mathrm{Sn}-\mathrm{O}$ bond in $\mathrm{SnO}_{2}[16,17]$. This component provides further support for the conclusion that tin was mainly present as $\mathrm{SnO}_{2}$. The high-energy component (C) with a binding energy of $531.8 \mathrm{eV}$ corresponds to oxygen atoms chemisorbed at the surface [16,17]. The weight of each component is obtained by dividing the area of that component by the total area of the $\mathrm{O} 1 \mathrm{~s}$ spectrum. The weight of component A was $72.3 \%$, the weight of component B was $25.4 \%$, and that of component $\mathrm{C}$ was $2.3 \%$. This shows that the predominant constituent of the films was cerium oxide. The intensity of the $\mathrm{C}$ component is partly related to the amount of adsorbed water, which in turn is proportional to the porosity of the films.

\subsection{Optical Properties}

The normal-incidence reflectance and transmittance spectra, in the wavelength range $\lambda=250-850 \mathrm{~nm}$, are shown in Figure 4. The transmittance spectra are obtained by dividing the measured transmittance by that of a fused silica substrate. The optical properties of the films can be used to estimate their porosity. The columnar microstructure of the films indicates the presence of voids within the films, which results in the films being porous. These voids (pores) may be filled with moisture (water) or air. The average packing density $(p)$ is defined as the volume occupied by the solid part divided by the total volume occupied by the solid and voids. In the transparent region $(\lambda>500 \mathrm{~nm})$, the refractive index of a film $\left(n_{f}\right)$ can be estimated from the minima in the transmittance spectra. The relation between the refractive index of the film $(n f)$ and the packing density is given by [18]:

$$
n_{f}^{2}=\frac{(1-p) n_{v}^{4}+(1+p) n_{v}^{2} n_{s}^{2}}{(1+p) n_{v}^{2}+(1-p) n_{s}^{2}}
$$

where $n_{s}$ is the bulk refractive index of the solid material, and $n_{v}$ is the refractive index of the voids ( $n_{v}=1.33$ if the voids are filled with water or 1.0 if they are filled with air). The refractive index of the mixture film $\left(\mathrm{n}_{\mathrm{f}}=2.012\right)$ was obtained from the minimum in the transmittance (at $\lambda=572 \mathrm{~nm}$ ) using the equation for the transmittance of a thin film on a transparent substrate [19]. The bulk refractive index of $\mathrm{CeO}_{2}$ and $\mathrm{SnO}_{2}$ is 2.5 and 2.0 respectively [20,21]. The bulk refractive index of $\mathrm{CeO}_{2}$ and $\mathrm{SnO}_{2}$ along with the XPS results were used to calculated the bulk refractive index of the mixture and found to be 2.305. Using these values in Equation (1), the packing density of the mixture was found to be 0.783 (for water-filled pores) or 0.884 (for air-filled pores). The porosity $(P)$ is defined as: $P=1-p$. Thus, the porosity was in the range $11.6-21.7 \%$. While porosity for pure $\mathrm{CeO}_{2}[8]$ reported earlier was $32 \%$. 
Figure 4. Normal-incidence transmittance $(T)$ and reflectance $(R)$ spectra of a deposited film of thickness $220 \mathrm{~nm}$.

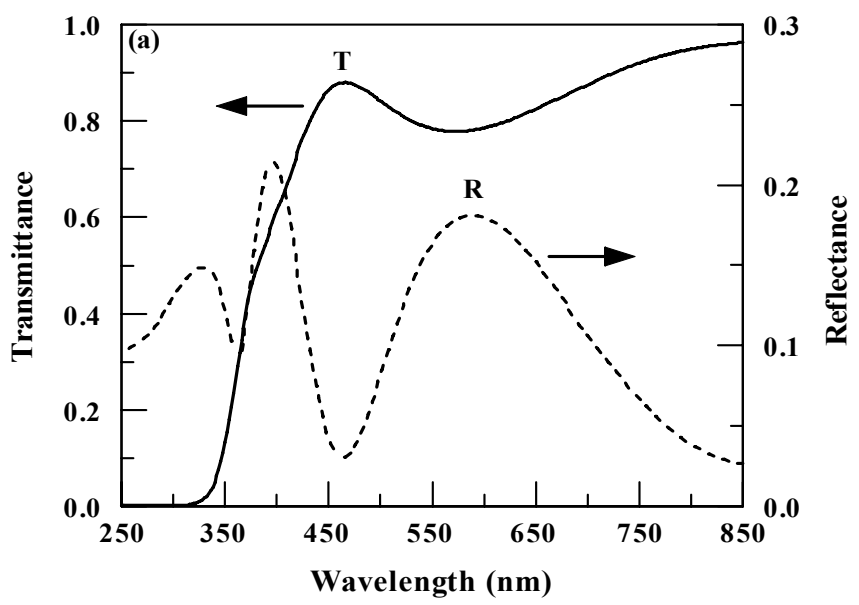

\subsection{Atomic Force Microscopy}

Figure 5 depicts the tapping mode AFM image of $\mathrm{SnO}_{2}$ mixed $\mathrm{CeO}_{2}$ thin film of thickness $220 \mathrm{~nm}$, annealed at a temperature of $500{ }^{\circ} \mathrm{C}$. The image reveals well separated conical nano columnar structure. This image has a measured roughness of (Area Ra $1.85 \mathrm{~nm}$ ) and (Area RMS $2.5 \mathrm{~nm}$ ), which shows that $\mathrm{SnO}_{2}$ mixed $\mathrm{CeO}_{2}$ films are highly porous with large surface area. This observation of high porosity confirms the similar findings of XPS and optical results discussed in Sections 3.1 and 3.2. The measured roughness reported earlier for pure $\mathrm{CeO}_{2}$ [10] was (Area $\mathrm{Ra} 2.38$ ) and (Area RMS 3.11).

Figure 5. Shows tapping mode AFM images of $\mathrm{SnO}_{2}$ doped $\mathrm{CeO}_{2}$ thin film. The film thickness was $220 \mathrm{~nm}$ and annealed at $500{ }^{\circ} \mathrm{C}$.

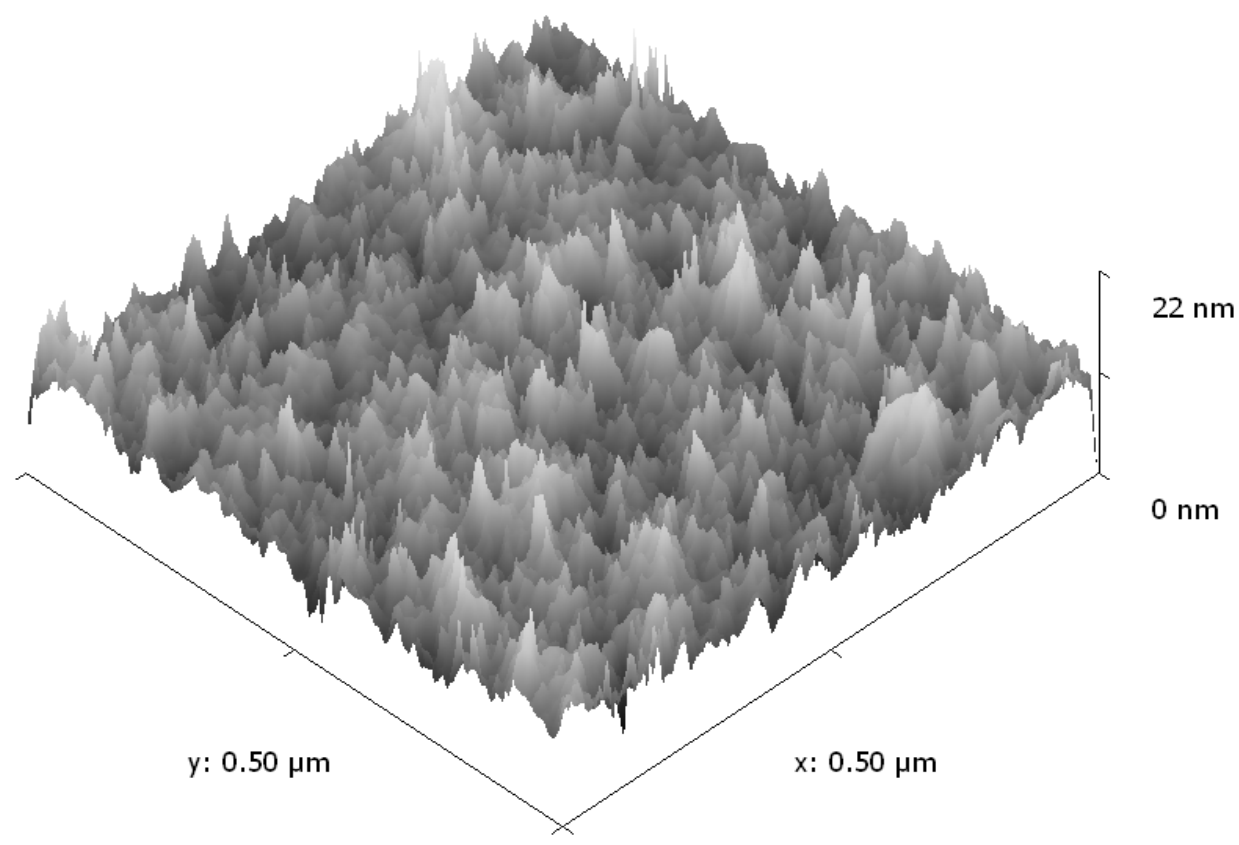




\subsection{CO Gas-Sensing Properties}

Interaction of gaseous species with a thin film includes two steps [22]. First, oxygen from the ambient adsorbs on the surface of the film, and extracts electrons from the material, ionizes to $\mathrm{O}_{2}^{-}, \mathrm{O}^{-}$ or $\mathrm{O}^{2-}$ depending on the operating temperature of the sensor $\left(T_{o p}\right)$ [23-25]. The second step involves the reaction of the tested gas (CO in present case) with the adsorbed oxygen species. The introduction of a reducing gas (such as $\mathrm{CO}$ ) decreases the resistance of the sensing film. For reducing gases, the sensitivity $S$ is defined as $\left(\Delta R / R_{C O}\right) \times 100$ where $\Delta R=\left(R_{\text {air }}-R_{C O}\right)$ [4], where $R_{\text {air }}$ is the resistance of the film in air, and $R_{\mathrm{CO}}$ is the resistance of the film in the presence of CO. The sensitivity was measured as a function of sensor temperature and biasing voltages for different $\mathrm{CO}$ concentrations. Figure 6 shows the dependence of the sensitivity on the sensor bias voltage for $\mathrm{SnO}_{2}$ mixed $\mathrm{CeO}_{2}$ sensor at the optimum temperature of $430{ }^{\circ} \mathrm{C}$, with a $\mathrm{CO}$ concentration of $500 \mathrm{ppm}$. Figure 6 depicts that there was significant variation in response for $\mathrm{SnO}_{2}$ mixed $\mathrm{CeO}_{2}$ sensor as the biasing voltages were increased.

Figure 6. Sensitivity as a function of biasing voltage for $\mathrm{SnO}_{2}$ mixed $\mathrm{CeO}_{2}$ sensor of thickness $220 \mathrm{~nm}, \mathrm{CO}$ concentration of $500 \mathrm{ppm}$ and temperature of $430{ }^{\circ} \mathrm{C}$.

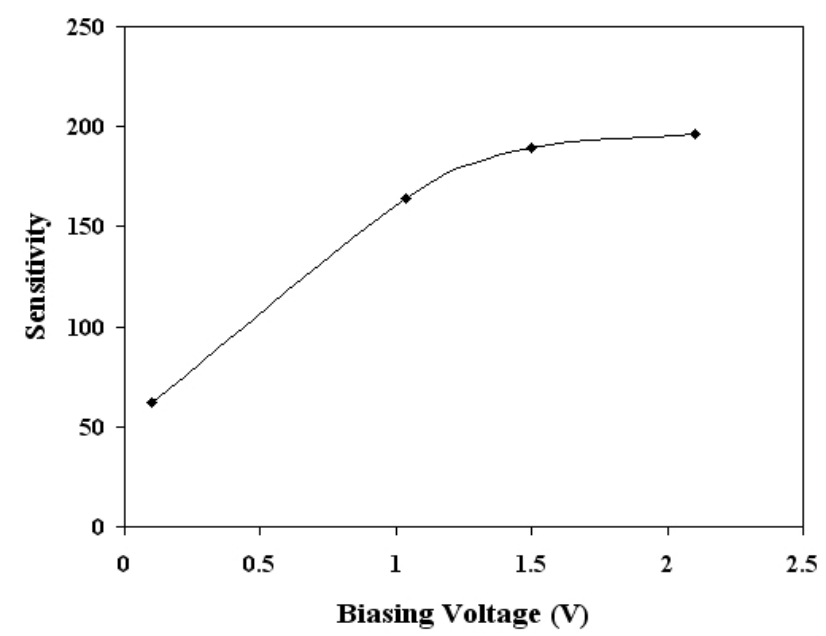

Similar results were observed for other temperatures in the range $300-500{ }^{\circ} \mathrm{C}$. Therefore, from these findings, the bias voltage was fixed at $1.5 \mathrm{~V}$ for subsequent experimental work. The effect of biasing voltages has been discussed in detail [10,26,27]. Briefly the effect of applied biasing voltage perhaps could be visualized as following; the applied biasing voltage would increase/decrease the Schottky barrier height (created by $\mathrm{O}^{-}$adsorption), which in turn would increase/decrease the threshold $\mathrm{CO}$ concentration for the $\mathrm{p}-\mathrm{n}$ or vice versa transitions. Figure 7 shows the sensitivity variation as a function of operating temperature (in the range $300{ }^{\circ} \mathrm{C}$ to $500{ }^{\circ} \mathrm{C}$ ) for $\mathrm{SnO}_{2}$ mixed $\mathrm{CeO}_{2}$ film of thickness $220 \mathrm{~nm}$ and $\mathrm{CO}$ concentrations of $500 \mathrm{ppm}$. The inset of Figure 7 shows the peak value of the sensitivity for $\mathrm{SnO}_{2}$ mixed $\mathrm{CeO}_{2}$ is $430{ }^{\circ} \mathrm{C}$. For the optimum operating temperatures $430{ }^{\circ} \mathrm{C}$, the dependence of sensitivity on $\mathrm{CO}$ gas concentration was also investigated. The results are given in Figure 8, which shows that the sensor was capable of detecting $\mathrm{CO}$ gas concentrations as low as 5 ppm. It is clearly evident from Figures 7 and 8 that the $\mathrm{SnO}_{2}$ mixed $\mathrm{CeO}_{2}$ thin film gas sensor was highly sensitive to $\mathrm{CO}$. 
Figure 7. Sensitivity as a function of temperature for $\mathrm{SnO}_{2}$ mixed $\mathrm{CeO}_{2}$. The $\mathrm{CO}$ concentrations and films thickness was $500 \mathrm{ppm}$ and $220 \mathrm{~nm}$ respectively.

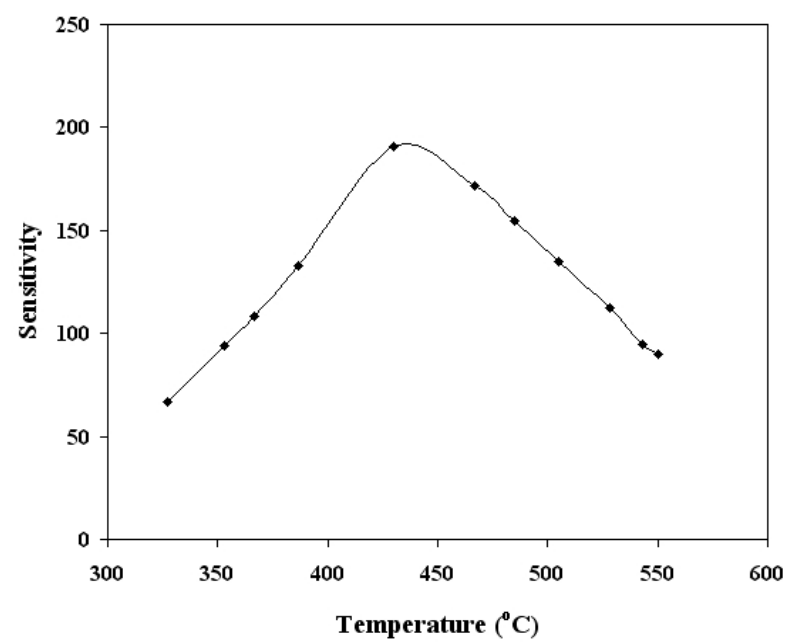

Figure 8. Response of the $\mathrm{SnO}_{2}$ mixed $\mathrm{CeO}_{2}$ thin film sensor to different $\mathrm{CO}$ concentrations. The film thickness was $220 \mathrm{~nm}$ and temperature of $430{ }^{\circ} \mathrm{C}$.

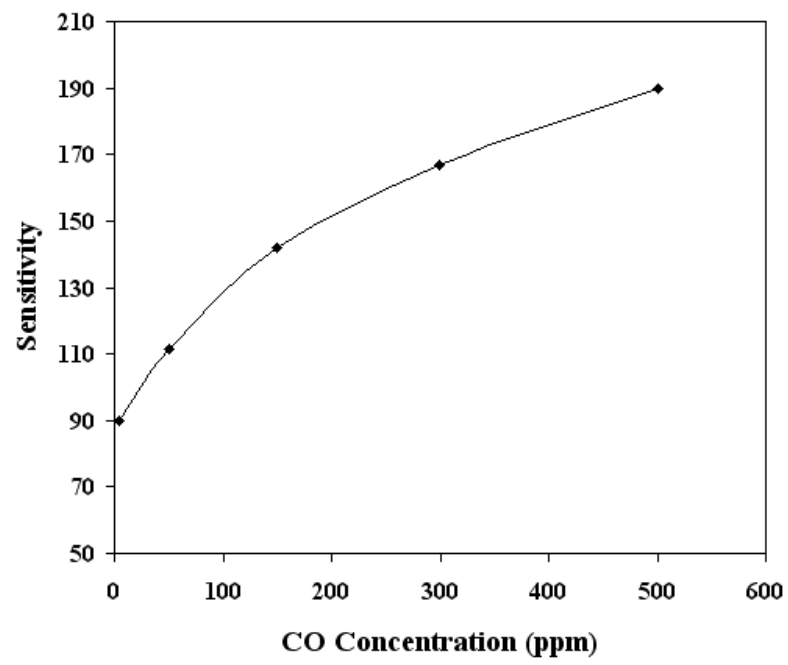

Figure 9. Current responses in time of $\mathrm{SnO}_{2}$ mixed $\mathrm{CeO}_{2}$ sensors exposed to 500 ppm of $\mathrm{CO}$ for a film thickness of $220 \mathrm{~nm}$ at the optimum temperature of $430{ }^{\circ} \mathrm{C}$.

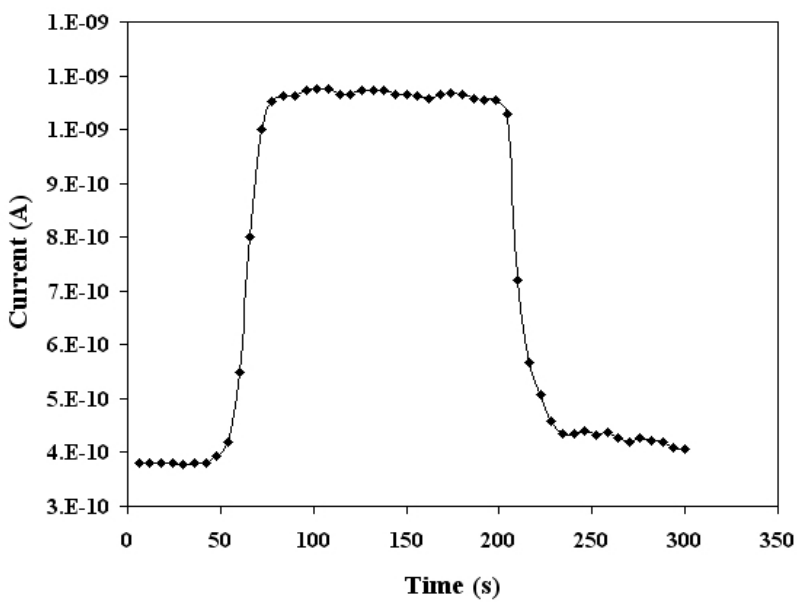


Figure 9 illustrates the dynamic current response of $\mathrm{SnO}_{2}$ mixed $\mathrm{CeO}_{2}$ sensor at the optimum temperature when exposed to $500 \mathrm{ppm}$ of $\mathrm{CO}$ mixed in dry air. It is clear from the Figure 9 that for $\mathrm{SnO}_{2}$ mixed $\mathrm{CeO}_{2}$ sensor it took 26 seconds for the current to reach to its maximum value (peak response time). The sensors recover back to their initial value within 30 seconds. Comparing these results with the same sensing parameters for pure $\mathrm{CeO}_{2}[10]$, there is significant improvement in response time and detection limit, while the operating temperature has also increased for $\mathrm{SnO}_{2}$ mixed $\mathrm{CeO}_{2}$ sensors.

\section{Discussion}

The gas sensing parameters of $\mathrm{SnO}_{2}$ mixed $\mathrm{CeO}_{2}$ can be compared with those of the pure $\mathrm{CeO}_{2}$ films [8]. In the present case $\mathrm{SnO}_{2}$ mixed $\mathrm{CeO}_{2}$ had an optimum operating temperature that was higher (by about $40{ }^{\circ} \mathrm{C}$ ) than that of pure $\mathrm{CeO}_{2}$. The response time for the $\mathrm{SnO}_{2}$ mixed $\mathrm{CeO}_{2}$ was much shorter than the pure $\mathrm{CeO}_{2}$, while the sensor recovery time for the two sensors were approximately the same. Also, there were significant differences in the $\mathrm{CO}$ gas detection limits. The $\mathrm{SnO}_{2}$ mixed $\mathrm{CeO}_{2}$ sensor was capable of detecting as small as 5 ppm of $\mathrm{CO}$ easily comparing with pure $\mathrm{CeO}_{2}$ sensors [10]. Although for pure $\mathrm{CeO}_{2}$ both surface roughness and porosity is higher than $\mathrm{SnO}_{2}$ mixed $\mathrm{CeO}_{2}$ and higher porosity and surface roughness enhances film sensitivity. However another important factor of acid-base reaction may have contributed in the improvement of sensing parameters for $\mathrm{SnO}_{2}$ mixed $\mathrm{CeO}_{2}$. The gas sensitivity in addition to porosity and surface roughness has also been related to the reactivity of the gas molecules over the sensing surface as determined by the acid-base character of the sensing surface. It was found that the basicity of the surface decreases as its electronegativity $(\chi)$ increases [28,29]. Increasing basicity increases the adsorption of the reducing gases such as CO. Thus decrease of the basicity of the surface leads to a reduction of the conversion efficiency of reducing gases such as $\mathrm{CO}[28,29]$. Therefore the improved sensing parameters of $\mathrm{SnO}_{2}$ mixed $\mathrm{CeO}_{2}$ oxide could be due to the basicity of $\mathrm{SnO}_{2}$ mixed $\mathrm{CeO}_{2}$ which is much higher than the basicity of pure $\mathrm{CeO}_{2}$ [30]. Thus sensitivity in general depends on combination of several parameters discussed above; however it is possible that in specific cases one parameter may dominant the other.

\section{Conclusions}

Mixed metal-oxide thin films of tin oxide mixed cerium oxide were prepared by co-evaporation and were subsequently annealed in air at $500{ }^{\circ} \mathrm{C}$ for two hours. The thickness of the films was $220 \mathrm{~nm}$. The films were amorphous with a uniform nano columnar structure. XPS measurements revealed that the films consisted of $\mathrm{SnO}_{2}$ and $\mathrm{CeO}_{2}$. The atomic concentration of the elements was calculated from the normalized areas of the peaks, taking the atomic sensitivity factors into account. The accuracy of determining this ratio is $10 \%$. The atomic concentrations were $20 \%$ for cerium, $13 \%$ for tin, and $67 \%$ for oxygen. The XPS $\mathrm{O} 1 \mathrm{~s}$ peak consisted of components arising from $\mathrm{CeO}_{2}$ and $\mathrm{SnO}_{2}$, as well as a component arising from adsorbed oxygen species. The presence of this component is an indication of the porosity of the films. Porosity was calculated using optical techniques, and was found to be in the range of 11.6-21.7\%. AFM results indicated that $\mathrm{SnO}_{2}$ mixed $\mathrm{CeO}_{2}$ thin films exhibit large nicely separated conical nano columnar structure with the measured roughness of (Area RMS $2.5 \mathrm{~nm}$ ). Such rough and porous films with increased basicity are highly suitable for gas sensing applications. The 
$\mathrm{CO}$ gas sensing properties of the $\mathrm{SnO}_{2}$ mixed $\mathrm{CeO}_{2}$ films were investigated. The optimum operating temperature, for a $\mathrm{CO}$ concentration of $500 \mathrm{ppm}$, was $430{ }^{\circ} \mathrm{C}$. For this optimum temperature, the sensitivity of the films was found to be proportional to the $\mathrm{CO}$ concentration, and saturated for $\mathrm{CO}$ concentration higher than 5,000 ppm. The films were capable of detecting $\mathrm{CO}$ concentrations as low as $5 \mathrm{ppm}$. The response and recovery times were found to be $26 \mathrm{~s}$ and $30 \mathrm{~s}$ respectively. Such times are considered to be adequately fast for gas-sensing applications.

\section{Acknowledgments}

The support provided by the Deanship of Scientific Research and the Physics Department of King Fahd University of Petroleum and Minerals is acknowledged. This work is part of project No. PH/CERIUM/355.

\section{References}

1. Kim, I.J.; Han, S.D.; Singh, I.; Lee, H.D. Sensitivity enhancement for CO gas detection using a $\mathrm{SnO}_{2}-\mathrm{CeO}_{2}-\mathrm{PdO}$ system. Sens. Actuat. B 2005, 107, 825-830.

2. Khodadadi, A.; Mohajerzadek, S.S.; Mortazavi, Y.; Miri, A.M. Cerium oxide/ $/ \mathrm{SnO}_{2}$-based semiconductor gas sensors with improved sensitivity to CO. Sens. Actuat. B 2001, 80, 267-271.

3. Barreca, D.; Gasparotto, A.; Maccato, C.; Maragno, C.; Tondello, E.; Comini, E.; Sberveglieri, G. Columnar $\mathrm{CeO}_{2}$ nanostructures for sensor application. Nanotechnology 2007, 18, 125502-125508.

4. Becker, T.; Ahlers, S.; Bosch-v.Braünmuhl, C.; Müller, G.; Kiesewetter, O. Gas sensing properties of thin-and thick-film tin-oxide materials. Sens. Actuat. B 2001, 77, 55-61.

5. Sharma, R.K.; Chan, P.C.H.; Tang, Z.; Yan, G.; Hsing, I.M.; Sin, J.K.O. Sensitive, selective and stable tin dioxide thin-films for carbon monoxide and hydrogen sensing in integrated gas sensor array applications. Sens. Actuat. B 2001, 72, 160-166.

6. Mandayo, G.G.; Castaño, E.; Gracia, F.J.; Cirera, A.; Cornet, A.; Morante, J.R. Strategies to enhance the carbon monoxide sensitivity of tin oxide thin films. Sens. Actuat. B 2003, 95, 90-96.

7. Park, S.S.; Mackenzie, J.D. Thickness and microstructure effects on alcohol sensing of tin oxide thin films. Thin Solid Films 1996, 274, 154-159

8. Sakai, G.; Baik, N.S.; Miura, N.; Yamazoe, N. Gas sensing properties of tin oxide thin films fabricated from hydrothermally treated nanoparticles: Dependence of $\mathrm{CO}$ and $\mathrm{H}_{2}$ response on film thickness. Sens. Actuat. B 2001, 77, 116-121.

9. Wurzinger, O.; Reinhardt, G.; CO-sensing properties of doped $\mathrm{SnO}_{2}$ sensors in $\mathrm{H}_{2}$-rich gases. Sens. Actuat. B 2004, 103, 104-110.

10. Durrani, S.M.A.; Al-Kuhaili, M.F.; Bakhtiari, I.A. Carbon monoxide gas-sensing properties of electron-beam deposited cerium oxide thin films. Sens. Actuat. B 2008, 134, 934-939.

11. Khawaja, E.E.; Durrani, S.M.A.; Al-Kuhaili, M.F. Determination of average refractive index of thin $\mathrm{CeO}_{2}$ films with large imhomogeneties. J. Phys. D 2003, 36 545-551.

12. Briggs, D.; Grant, J.T. Surface Analysis by Auger and X-Ray Photoelectron Spectroscopy; IM Publications: Chichester, UK, 2003.

13. Yuzhakova, T.; Rakic, V.; Guimon, C.; Auroux, A. Preparation and characterization of $\mathrm{Me}_{2} \mathrm{O}_{3}$ $\mathrm{CeO}_{2}(\mathrm{Me}=\mathrm{B}, \mathrm{Al}, \mathrm{Ga}, \mathrm{In})$ mixed-oxide catalysts. Chem. Mater. 2007, 19, 2970-2981. 
14. Kobayashi, Y.; Fujiwara, Y.J. Chemical deposition of cerium oxide thin films on nickel substrate from aqueous solution. Alloys Compounds 2006, 408-412, 1157-1160.

15. Trinchi, A.; Li, Y.X.; Wlodarski, W.; Kaciulis, S.; Pandolfi, L.; Viticoli, S.; Comini, E.; Sberveglieri, G. Investigation of sol-gel prepared $\mathrm{CeO}_{2}-\mathrm{TiO}_{2}$ thin films for oxygen gas sensing. Sens. Actuat. B 2003, 95, 145-150.

16. Szuber, J.; Czempik, G.; Larciprete, R.; Koziej, D.; Adamowicz, B. XPS study of the L-CVD deposited $\mathrm{SnO}_{2}$ thin films exposed to oxygen and hydrogen. Thin Solid Films 2001, 391, 198-203.

17. Kwoka, M.; Ottaviano, L.; Passacantando, M.; Santucci, S.; Czempik, G.; Szuber, J. XPS study of the surface chemistry of L-CVD $\mathrm{SnO}_{2}$ thin films after oxidation. Thin Solid Films 2005, 490, 36-42.

18. Harris, M.; Macleod, H.A.; Ogura, S.; Pelletier, E.; Vidal, B. The relationship between optical inhomogeneity and film structure. Thin Solid Films 1979, 57, 173-178.

19. Heavens, O.S. Optical Properties of Thin Solid Films; Dover: New York, NY, USA, 1991.

20. Netterfield, R.P.; Sainty, W.G.; Martin, P.J.; Sie, S.H. Properties of $\mathrm{CeO}_{2}$ thin films prepared by oxygen-ion-assisted deposition. Appl. Opt. 1985, 24, 2267-2272.

21. Shackelford, J.F.; Alexander, W. Handbook of Materials Science, 3rd ed.; CRC: Boca Raton, FL, USA, 2000.

22. Bittencourt, C.; Llobet, E.; Silva, M.A.P.; Landers, R.; Nieto, L.; Vicaro, K.O.; Sueiras, J.E.; Calderer, J.; Correig, X. Influence of the deposition method on the morphology and elemental composition of $\mathrm{SnO}_{2}$ films for gas sensing: Atomic force and X-ray photoemission spectroscopy analysis. Sens. Actuat. B 2003, 92, 67-72.

23. Ghimbeu, C.M.; Schoonman, J.; Lumbreras, M.; Siadat, M. Electrostatic spray deposited zinc oxide films for gas sensor applications. Appl. Surf. Sci. 2007, 253, 7483-7489.

24. Ferro, R.; Rodriguez, J.A.; Jimenez, I.; Cirera, A.; Cerda, J.; Morante, J.R. Gas sensing properties of sprayed films of $(\mathrm{CdO}) x(\mathrm{ZnO})_{1-x}$ mixed oxide. IEEE Sens. J. 2005, 5, 48-52.

25. Gong, H.; Hu, J.Q.; Wang, J.H.; Ong, C.H.; Zhu, F.R. Nano-crystalline Cu-doped ZnO thin film gas sensor for CO. Sens. Actuat. B 2006, 115, 247-251.

26. Durrani, S.M.A. Biasing Voltage dependence of sensitivity of electron beam evaporated $\mathrm{SnO}_{2}$ thin film CO sensor. Sensors 2006, 6, 1153-1160.

27. Durrani, S.M.A.; Al-Kuhaili, M.F. Effect of Biasing Voltages and electrode metals on the sensitivity of electron beam evaporated $\mathrm{HfO}_{2}$ thin film $\mathrm{CO}$ sensor. Mater. Chem. Phys. 2008, 109, $56-60$.

28. Tang, H.; Yan, M.; Zhang, H. Li S.; Ma, X.; Wang, M.; Yang, D. A selective $\mathrm{NH}_{3}$ gas sensor based on $\mathrm{Fe}_{2} \mathrm{O}_{3}-\mathrm{ZnO}$ nanocomposites at room temperature. Sens. Actuat. B 2006, 114, 910-915.

29. Neri, G.; Bonavita, A.; Rizzo, G.; Galvagno, S.; Capone, S.; Siciliano, P. Methanol gas-sensing properties of $\mathrm{CeO}_{2}-\mathrm{Fe}_{2} \mathrm{O}_{3}$ thin films. Sens. Actuat. B 2006, 114, 687-695.

30. Jyothi, T.M.; Talawar, M.B.; Rao, B.S. Formation of anisaldehyde via hydroxymethylation of anisole over $\mathrm{SnO}_{2}-\mathrm{CeO}_{2}$ catalysts. Catal. Lett. 2000, 64, 151-155.

(C) 2012 by the authors; licensee MDPI, Basel, Switzerland. This article is an open access article distributed under the terms and conditions of the Creative Commons Attribution license (http://creativecommons.org/licenses/by/3.0/). 